\title{
Chlorogenic acid prevents acetaminophen-induced liver injury: the involvement of CYP450 metabolic enzymes and some antioxidant signals"
}

\author{
Chun PANG ${ }^{1,2}$, Yu-chen $\mathrm{SHENG}^{3}$, Ping JIANG ${ }^{1}$, Hai WEI ${ }^{2}$, Li-li JI ${ }^{\dagger \dagger 1}$ \\ (' Shanghai Key Laboratory of Complex Prescription, the MOE Key Laboratory for Standardization of Chinese Medicines, \\ Institute of Chinese Materia Medica, Shanghai University of Traditional Chinese Medicine, Shanghai 201203, China) \\ $\left({ }^{2}\right.$ Center for Traditional Chinese Medicine and Systems Biology, Shanghai University of Traditional Chinese Medicine, Shanghai 201203, China) \\ $\left({ }^{3}\right.$ Center for Drug Safety Evaluation and Research, Shanghai University of Traditional Chinese Medicine, Shanghai 201203, China) \\ †E-mail: lichenyue1307@126.com \\ Received Dec. 9, 2014; Revision accepted Mar. 12, 2015; Crosschecked June 16, 2015
}

\begin{abstract}
Chlorogenic acid (CGA), a polyphenolic compound, is abundant in fruits, dietary vegetables, and some medicinal herbs. This study investigated the prevention of CGA against acetaminophen (AP)-induced hepatotoxicity and its engaged mechanisms. CGA reversed the decreased cell viability induced by AP in L-02 cells in vitro. In addition, CGA reduced the AP-induced increased serum levels of alanine/aspartate aminotransferase (ALT/AST) in vivo. The effect of CGA on cytochrome P450 (CYP) enzymatic (CYP2E1, CYP1A2, and CYP3A4) activities showed that CGA caused very little inhibition on CYP2E1 and CYP1A2 enzymatic activities, but not CYP3A4. The measurement of liver malondialdehyde (MDA), reactive oxygen species (ROS), and glutathione (GSH) levels showed that CGA prevented AP-induced liver oxidative stress injury. Further, CGA increased the AP-induced decreased mRNA expression of peroxiredoxin (Prx) 1, 2, 3, 5, 6, epoxide hydrolase (Ephx) 2, and polymerase (RNA) II (DNA directed) polypeptide $K$ (Polr2k), and nuclear factor erythroid-2-related factor 2 (Nrf2). In summary, CGA ameliorates the AP-induced liver injury probably by slightly inhibiting CYP2E1 and CYP1A2 enzymatic properties. In addition, cellular important antioxidant signals such as Prx1, 2, 3, 5, 6, Ephx2, Polr2k, and Nrf2 also contributed to the protection of CGA against AP-induced oxidative stress injury.
\end{abstract}

Key words: Chlorogenic acid, Acetaminophen, CYP450, Oxidative stress injury doi: $10.1631 /$ jzus.B1400346

\section{Introduction}

Acetaminophen (AP), a common over-the-counter (OTC) drug, is widely used in clinical practice as an

\footnotetext{
¿ Corresponding author

* Project supported by the National Natural Science Foundation of China (No. 81322053), the Program for New Century Excellent Talents in University (No. NCET-11-1054), the "Shu Guang" Project of Shanghai Municipal Education Commission and Shanghai Education Development Foundation (No. 13SG43), and the State Major Science and Technology Special Projects during the 12th Five-Year Plan (No. 2012ZX09505001-002), China

(D) ORCID: Li-li JI, http://orcid.org/0000-0001-6159-2626

(C) Zhejiang University and Springer-Verlag Berlin Heidelberg 2015
}

analgesic-antipyretic drug. However, an overdose of AP will cause severe liver injury (Lee, 2004). This adverse effect has become the major cause of druginduced liver injury in the United States and the United Kingdom (Lee, 2003). $N$-acetylcysteine (NAC) is generally used for the treatment of AP-induced hepatotoxicity, although it has a drawback as it must be given within $8 \mathrm{~h}$ after AP intoxication, and it can also cause other side-effects including vomiting, nausea, and even shock (Bajt et al., 2004; Bebarta et al., 2010). Therefore, the need for alternative, more effective, and widely applicable antidotes for APinduced liver injury is warranted. 
Chlorogenic acid (CGA) is the major active ingredient found in many traditional Chinese medicines such as Folium mori (Hunyadi et al., 2012) and Flos Lonicerae japonicae (Oku et al., 2011), and it is also abundant in some fruits, dietary vegetables (Kasai et al., 2000; Gavrilova et al., 2011), and daily beverages like coffee (del Rio et al., 2010). CGA has been reported to possess anti-bacterial, antioxidant, and anti-carcinogenic properties (Kono et al., 1997; dos Santos et al., 2006). CGA has also been reported to be a potent polyphenolic antioxidant because it contains a certain amount of the R-OH group (Fig. 1a), which can bind with hydroxyl radicals and superoxide anion radicals to protect cells from oxidative injury (Özyürek et al., 2008).

Our previous study has found that CGA can prevent AP-induced liver injury through regulating liver glutathione (GSH) and thioredoxin (Trx) antioxidant systems (Ji et al., 2013). However, whether there is some other antioxidant signals involved in the protection of CGA against AP-induced liver injury has not been identified. Liver CYP2E1, CYP1A2, and CYP3A4 have been reported to be the key metabolic enzymes responsible for metabolizing AP (Laine et al., 2009). In this present study, we observed the protection of CGA against AP-induced hepatotoxicity in vitro and in vivo, and then observed the potential effects of CGA on CYP2E1, CYP1A2, and CYP3A4 enzymatic properties and their expression, and finally observed the involvement of some antioxidant signals in the protection of CGA against AP-induced liver injury.

\section{Materials and methods}

\subsection{Materials}

CGA (5-caffeoylquinic acid, CAS-327-97-9) (Fig. 1a), with $98 \%$ purity, was purchased from the Shanghai Hitsanns Co., Ltd. (Shanghai, China). AP, CYP450 inhibitors including sodium diethyldithiocarbamate trihydrate (DDTC), furafylline, and ketoconazole, and 5,5'-dithio-bis-(2-nitrobenzoic acid) (DTNB) were purchased from the Sigma Chemical Co. (St. Louis, MO, USA). Nicotinamide adenine dinucleotide phosphate (NADPH) was purchased from Roche Diagnostics GmbH (Mannheim, Germany). Alanine/aspartate aminotransferase (ALT/AST), malondialdehyde (MDA) analysis kits were pur- chased from the Nanjing Jiancheng Bioengineering Institute (Nanjing, China). PrimeScript ${ }^{\circledR}$ RT Master Mix and SYBR $^{\circledR}$ Premix Ex Taq ${ }^{\mathrm{TM}}$ were purchased from TaKaRa (Shiga, Japan). Vivid ${ }^{\circledR}$ CYP2E1, Vivid $^{\circledR}$ CYP1A2, and Vivid ${ }^{\circledR}$ CYP3A4 kits, 2',7'dichlorodihydrofluorescein diacetate (H2DCFDA), and Trizol reagent were all purchased from Life Technology (Carlsbad, CA, USA). All other reagents were purchased from Sigma (St. Louis, MO, USA), unless otherwise indicated.

\subsection{Cell culture}

L-02 cells (Cell Bank, Type Culture Collection of Chinese Academy of Sciences, Shanghai, China), a human normal liver cell line, were maintained in RPMI 1640 medium containing $10 \%$ fetal bovine serum (FBS), $50 \mathrm{U} / \mathrm{ml}$ penicillin, and $50 \mathrm{mg} / \mathrm{ml} \mathrm{strep-}$ tomycin in an atmosphere of $5 \% \mathrm{CO}_{2}$ at $37{ }^{\circ} \mathrm{C}$.

\subsection{Cell viability assay}

Cells were pre-incubated with various concentrations of CGA for $15 \mathrm{~min}$ after adherent, and then incubated with AP for another $48 \mathrm{~h}$. After treatments, $500 \mu \mathrm{g} / \mathrm{ml}$ 3-(4,5-dimethylthiazol-2-yl)-2,5-diphenyltetrazolium bromide (MTT) was added, and $4 \mathrm{~h}$ later, 10\% SDS$5 \%$ iso-butanol- $0.01 \mathrm{~mol} / \mathrm{L} \mathrm{HCl}$ was added. At last the optical density was measured at 570 and $630 \mathrm{~nm}$, and cell viability ( $\%$ of control) was calculated.

\subsection{CYP450 metabolic enzyme activity assay}

The effects of CGA on CYP2E1, CYP1A2, and CYP3A4 enzymatic activities were analyzed by using Vivid $^{\circledR}$ CYP2E1, Vivid ${ }^{\circledR}$ CYP1A2, and Vivid $^{\circledR}$ CYP3A4 kits according to their descriptions. The CYP450 positive inhibitor used for CYP2E1 is DDTC $(1 \mathrm{mmol} / \mathrm{L})$, for CYP1A2 it is furafylline $(10 \mu \mathrm{mol} / \mathrm{L})$, for CYP3A4 it is ketoconazole $(10 \mu \mathrm{mol} / \mathrm{L})$, respectively. The reaction rates are obtained by calculating the change in fluorescence per minute. The analysis of the results was performed with a Kinetic Assay Mode using the equation: inhibition of positive inhibitor $(\%)=[1-(X-B) /(A-B)] \times 100 \%$, where $X, A$, and $B$ represent the rates of the test compound CGA, solvent control, and positive inhibitor control, respectively.

\subsection{Animals and treatments}

Male imprinting control region (ICR) mice (specific pathogen-free, SPF), weighing 16-20 g, were 
purchased from the Shanghai Laboratory Animal Center of the Chinese Academy of Sciences (Shanghai, China). The mice were fed on a standard laboratory diet and supplied with water ad libitum at a temperature of $(22 \pm 1){ }^{\circ} \mathrm{C}$ with a 12 -h light and dark cycle and relative humidity of $(65 \pm 5) \%$.

The mice were randomly divided into five groups: vehicle control, AP (300 mg/kg), AP+CGA $(10 \mathrm{mg} / \mathrm{kg}), \mathrm{AP}+\mathrm{CGA}(40 \mathrm{mg} / \mathrm{kg})$, and CGA (40 mg/kg) (with $n=8$ each group). Mice were pre-administered orally with the vehicle control or 10 or $40 \mathrm{mg} / \mathrm{kg} \mathrm{CGA}$ for $7 \mathrm{~d}$. On the last day, the mice were given a single dose of AP (300 mg/kg, intragastric (i.g.)) $1 \mathrm{~h}$ after administration of CGA. The mice were then killed $4 \mathrm{~h}$ after AP injection, and plasma and liver tissue were collected.

\subsection{ALT/AST assay}

Fresh blood obtained from the mice was allowed to clot for $2 \mathrm{~h}$, and then serum was collected by centrifuging. Serum ALT and AST levels were determined by kits according to the manufacturer's instructions.

\subsection{Liver MDA amount assay}

Liver homogenates were prepared in cold phosphate buffer solution (PBS). Liver MDA amount was determined by kits according to the manufacturer's instructions, then calculated based on the tissue protein concentration.

\subsection{Determination of liver GSH levels}

Liver homogenates were prepared in cold PBS. Liver GSH levels were determined by the DTNB assay according to our previous reported method (Liang et al., 2011).

\subsection{Determination of liver ROS levels}

Liver ROS were measured with the probe H2DCFDA. Briefly, the livers were homogenized in cold PBS, centrifuged at $4{ }^{\circ} \mathrm{C}, 600 \mathrm{~g}$ for $10 \mathrm{~min}$. The supernatant was further centrifuged at $4{ }^{\circ} \mathrm{C}, 10000 \mathrm{~g}$ for $15 \mathrm{~min}$, and the precipitation was incubated with $10 \mu \mathrm{mol} / \mathrm{L} \mathrm{H} 2 \mathrm{DCFDA}$ in the dark at room temperature for $1 \mathrm{~h}$, and then fluorescence was immediately read at excitation $(485 \pm 20) \mathrm{nm}$, emission $(525 \pm 20) \mathrm{nm}$ by using a spectrophotometer (BioTek Synergy H4). Protein concentrations in the supernatant were assayed, and all the results were calculated as units of fluorescence per milligram of protein.

\subsection{Real-time polymerase chain reaction (PCR) analysis}

Liver homogenates were prepared in a Trizol regent, and total RNA was extracted according to the manufacturer's instructions. Complementary DNA (cDNA) was synthesized by using a PrimeScript ${ }^{\mathrm{TM}}$ RT Master Mix kit. Real-time PCR was performed by SYBR Green Premix kits on Step-One-Plus (Applied Biosystems, USA). Relative expression of target genes was normalized to $A c t b$, analyzed by the $2^{-\Delta \Delta C_{\mathrm{T}}}$ method and given as a ratio compared to the vehicle control. The primer sequences are listed as Table 1.

Table 1 Primers for real-time PCR

\begin{tabular}{|c|c|}
\hline Target & Primer sequence \\
\hline \multirow[t]{2}{*}{$A c t b$} & F: 5'-TTCGTTGCCGGTCCACACCC-3' \\
\hline & R: 5'-GCTTTGCACATGCCGGAGCC-3' \\
\hline \multirow[t]{2}{*}{$\operatorname{Prdx} 1$} & F: 5'-CACCCAAGAAACAAGGAGGA-3' \\
\hline & R: 5'-AAAAAGGCCCCTGAAAGAGA-3' \\
\hline \multirow[t]{2}{*}{$\operatorname{Prdx} 2$} & F: 5'-TGATGAGGGCATTGCTTACAGG-3' \\
\hline & R: 5'-GAGCGTCCCACAGGTAGGTCAT-3' \\
\hline \multirow[t]{2}{*}{$\operatorname{Prdx} 3$} & F: 5'-TTCCCACTTCAGTCATCTTGCC-3' \\
\hline & R: 5'-ATGCCAGCACTTTCCAACAG-3' \\
\hline \multirow[t]{2}{*}{$\operatorname{Prd} x 4$} & F: 5'-TTCCTGTTGCGGACCGAAT-3' \\
\hline & R: 5'-TACACTTGTCCACCAGCGTAGAA-3' \\
\hline \multirow[t]{2}{*}{$\operatorname{Prd} x 5$} & F: 5'-GGAAGGCGACAGACTTATTATTGG-3' \\
\hline & R: 5'-CCTTCACTATGCCGTTGTCTATCAC-3' \\
\hline \multirow[t]{2}{*}{$\operatorname{Prdx} 6$} & F: 5'-GCACCACAGAACTTGGCAGAG-3' \\
\hline & R: 5'-CCAGGCAAGATGATCCTCAACA-3' \\
\hline \multirow[t]{2}{*}{ Ephx2 } & F: 5'-CCTTCCAGCTTCGTGTCTGT-3' \\
\hline & R: 5'-TCCCTCTGGGAATTCCGTCT-3' \\
\hline \multirow[t]{2}{*}{ Polr $2 k$} & F: 5'-TTGTGGAGAGTGTCACACCG-3' \\
\hline & R: 5'-ACTCCCACATTTCATCGAGCA-3' \\
\hline \multirow[t]{2}{*}{ Fmo5 } & F: 5'-CAAGGACGCTGGGCCACTCAA-3' \\
\hline & R: 5'-CCTGGATGGTATGACGCTGGCT-3' \\
\hline \multirow[t]{2}{*}{ Mt1 } & F: 5'-CTCCGTAGCTCCAGCTTCAC-3' \\
\hline & R: 5'-AGGAGCAGCAGCTCTTCTTG-3' \\
\hline \multirow[t]{2}{*}{ Mt2 } & F: 5'-CCGATCTCTCGTCGATCTTC-3' \\
\hline & R: 5'-AGGAGCAGCAGCCTTTTCTTG-3' \\
\hline \multirow[t]{2}{*}{ Sod1 } & F: 5'-CCAGCATGGGTTCCACGTCCAT-3' \\
\hline & R: 5'-TCCGCCGGGCCACCATGTTT-3' \\
\hline \multirow[t]{2}{*}{ Sod2 } & F: 5'-CCACGCGGGCCTACGTGAACA-3' \\
\hline & R: 5'-TGCAGGCTGAAGAGCGACCTG-3' \\
\hline \multirow[t]{2}{*}{ Cyp2e1 } & F: 5'-GGCGCATCGTGGTCCTGCAT-3' \\
\hline & R: 5'-GGCTGGCCTTTGGTCTTTTTGAGC-3' \\
\hline \multirow[t]{2}{*}{ Cypla2 } & F: 5'-AGGGACACCTCACTGAATGGC-3' \\
\hline & R: 5'-GGGTCTTTCCACTGCTTCTCATC-3' \\
\hline \multirow[t]{2}{*}{ Cyp3a11 } & F: 5'-GAACTTCTCCTTCCAGCCTTGTAAG-3' \\
\hline & R: 5'-CGTGGCACAACCTTTAGAACAAT-3' \\
\hline \multirow[t]{2}{*}{ Nfe $2 l 2$} & F: 5'-TCTCCTCGCTGGAAAAAGAA-3' \\
\hline & R: 5'-AATGTGCTGGCTGTGCTTTA-3' \\
\hline
\end{tabular}

F: forward; R: reverse 


\subsection{Statistical analysis}

Data were expressed as mean \pm standard error of mean (SEM). The significance of differences between groups was evaluated by one-way analysis of variance (ANOVA) with the least significant difference (LSD) post-hoc test; and $P<0.05$ was considered as statistically significant.

\section{Results}

\subsection{Effect of CGA on AP-induced hepatotoxicity in vitro and in vivo}

As shown in Fig. 1b, AP (10 mmol/L) decreased cell viability dramatically as compared with the control
$(P<0.001)$, whereas various concentrations of CGA $(1,10,25,50$, and $100 \mu \mathrm{mol} / \mathrm{L})$ can reverse the APinduced decreased cell viability in a concentration-dependent manner $(P<0.05, P<0.01$, or $P<0.001)$. Further results of serum ALT/AST analysis showed that AP increased serum ALT and AST activities $(P<0.001)$, whereas $40 \mathrm{mg} / \mathrm{kg}$ CGA reduced the AP-induced increased ALT and AST activities $(P<0.05$ or $P<0.01)$ (Fig. 1c).

\subsection{Effect of CGA on CYP450 metabolic enzymes}

First, we observed whether CGA (40 mg/kg) will affect the liver mRNA expression of CYP2E1, CYP1A2, and CYP3A11 (CYP3A4 in humans) in mice. The results (Fig. 2a) showed that there were no (a)<smiles>O=C(O)OC1CC(O)(O)CC(O)C1O</smiles>

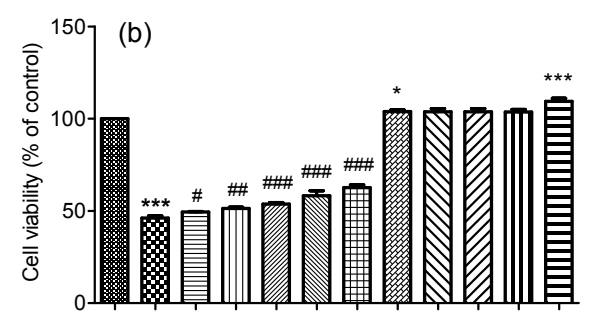

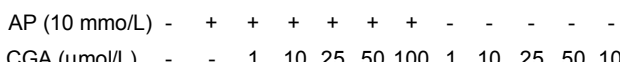

(c)

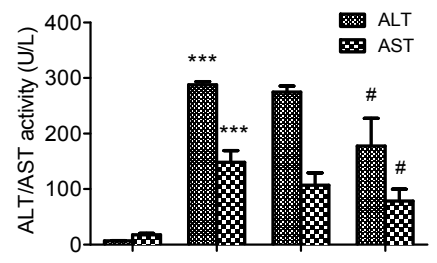

$\mathrm{AP}(300 \mathrm{mg} / \mathrm{kg})$ CGA $(\mathrm{mg} / \mathrm{kg})$

Fig. 1 Effect of CGA on AP-induced hepatotoxicity in vitro and in vivo

(a) Chemical structure of CGA. (b) L-02 cells were pre-incubated with CGA for 15 min, and followed by incubation with AP $(10 \mathrm{mmol} / \mathrm{L})$ for $48 \mathrm{~h}$. Cell viability was determined by the MTT method. Data are expressed as mean $\pm \operatorname{SEM}(n=5)$. (c) Mice were pre-administrated with CGA (10 and $40 \mathrm{mg} / \mathrm{kg}$ ) for 7 consecutive days, and a single dose of AP (300 mg/kg, i.g.) was given on the final day. Mice were sacrificed $4 \mathrm{~h}$ after AP treatment. Data are expressed as mean \pm SEM $(n=6-8)$. The results show that CGA ameliorates AP-induced hepatotoxicity in vitro and in vivo. ${ }^{*} P<0.05,{ }^{* * *} P<0.001$ compared with control; ${ }^{\#} P<0.05,{ }^{\# \#} P<0.01$, \#\#\# $P<0.001$ compared with only AP treatment
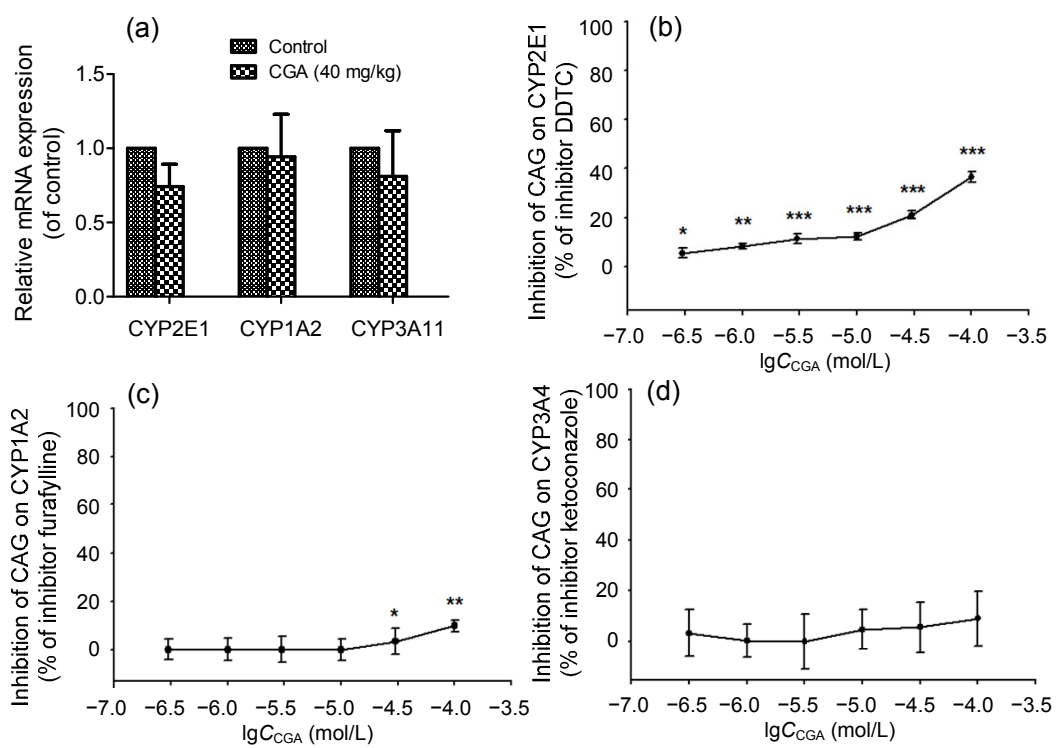

Fig. 2 Effects of CGA on liver mRNA expression and enzymatic activities of CYP2E1, CYP1A2, and CYP3A4 (a) CGA (40 mg/kg) performed no inhibition on liver mRNA expression of CYP2E1, CYP1A2, or CYP3A11. Data are expressed as mean $\pm \operatorname{SEM}(n=6)$. (b-d) Inhibition of CGA on the enzymatic activities of CYP2E1 (b), CYP1A2 (c), and CYP3A4 (d). Data are expressed as mean $\pm \operatorname{SEM}(n=6) .{ }^{*} P<0.05,{ }^{* *} P<0.01,{ }^{* * *} P<0.001$ compared with solvent control 


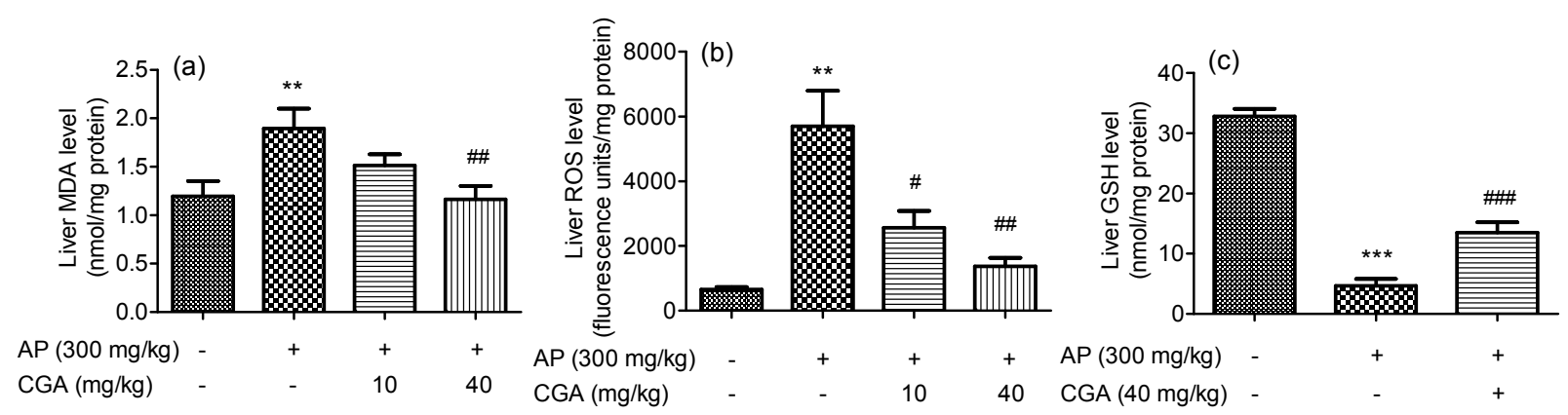

Fig. 3 Effect of CGA on AP-induced liver oxidative injury

(a) Liver MDA amount; (b) Liver ROS level; (c) Liver GSH amount. Data are expressed as mean \pm SEM ( $n=7-8$ ). The results show that CGA ameliorates AP-induced liver oxidative injury. ${ }^{* *} P<0.05,{ }^{* * *} P<0.001$ compared with control; ${ }^{\#} P<0.05$, ${ }^{\#} P<0.01$, \#\#\# $P<0.001$ compared with only AP treatment

obvious differences in the expression of CYP2E1, CYP1A2, or CYP3A11 in the liver between the control and CGA-treated mice.

Next, the enzymatic activities of CYP2E1, CYP1A2, and CYP3A4 were performed in vitro. As shown in Fig. 2b, CGA displayed less than $40 \%$ inhibition of the positive inhibitor control on CYP2E1 enzymatic activity $(P<0.05, P<0.01$, or $P<0.001)$, and such inhibition was in a concentration-dependent manner. CGA (30 or $100 \mu \mathrm{mol} / \mathrm{L}$ ) also had less than a $20 \%$ inhibition of positive inhibitor control on CYP1A2 enzymatic activity $(P<0.05$ or $P<0.01$; Fig. 2c). However, CGA had no inhibition on CYP3A4 enzymatic activity (Fig. 2d). These data suggest that the protection of CGA against AP-induced liver injury is probably caused by slightly inhibiting its metabolism.

\subsection{Effects of CGA on AP-induced liver oxidative stress injury}

As shown in Fig. 3, CGA (40 mg/kg) obviously reduced the increased liver MDA amounts induced by AP $(300 \mathrm{mg} / \mathrm{kg})(P<0.01)$. Furthermore, the formation of liver ROS was increased in AP $(300 \mathrm{mg} / \mathrm{kg})$-treated mice $(P<0.01)$, whereas CGA (10 and $40 \mathrm{mg} / \mathrm{kg})$ reduced such increase $(P<0.01, P<0.05)$. In addition, the liver GSH amount was decreased in AP $(300 \mathrm{mg} / \mathrm{kg})$-treated mice $(P<0.01)$, whereas CGA $(40 \mathrm{mg} / \mathrm{kg})$ reversed such a decrease $(P<0.001)$.

\subsection{Effect of CGA on some oxidative stress genes}

As shown in Fig. 4, AP $(300 \mathrm{mg} / \mathrm{kg})$ decreased liver mRNA expression of peroxiredoxin (Prx) 1, 2, 3, 5 , and $6(P<0.05$ or $P<0.01)$, but had no effect on Prx 4 mRNA expression. CGA $(40 \mathrm{mg} / \mathrm{kg})$ reversed the decreased expression of those above genes induced by AP $(P<0.05$ or $P<0.01)$.
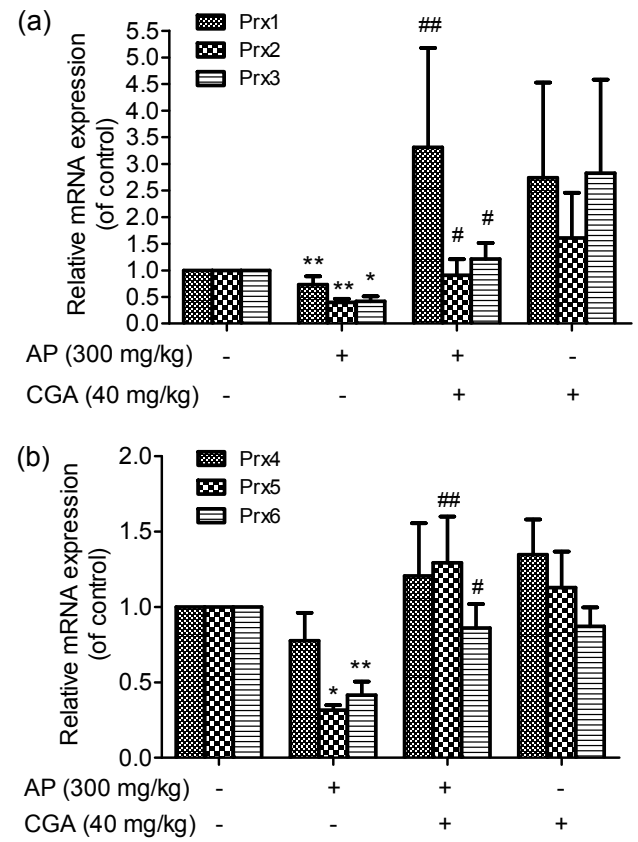

Fig. 4 Effect of CGA on liver Prx1-6 mRNA expression Liver mRNA expressions of Prx1-3 (a) and Prx4-6 (b) were detected by real-time PCR. Data are expressed as mean \pm SEM $(n=8) .{ }^{*} P<0.05,{ }^{* *} P<0.01$ compared with control; ${ }^{\sharp} P<0.05$, \# $P<0.01$ compared with only AP treatment

As shown in Fig. 5a, AP $(300 \mathrm{mg} / \mathrm{kg})$ decreased liver mRNA expression of epoxide hydrolase (Ephx) 2, polymerase (RNA) II (DNA directed) polypeptide $\mathrm{K}$ (Polr2k), and flavin-containing monooxygenase (Fmo5) $(P<0.05)$, whereas CGA $(40 \mathrm{mg} / \mathrm{kg})$ reversed the decreased expression of Ephx2 $(P<0.05)$ and Polr2k $(P<0.05)$, but not Fmo5 $(P>0.05)$. However, CGA itself can increase the Fmo5 gene expression $(P<0.05)$.

As shown in Fig. 5 b, AP $(300 \mathrm{mg} / \mathrm{kg})$ increased liver mRNA expression of metallothionein (MT) 1 $(P<0.05)$ and MT2 $(P<0.01)$, and CGA itself also slightly increased the MT1 expression. However, 

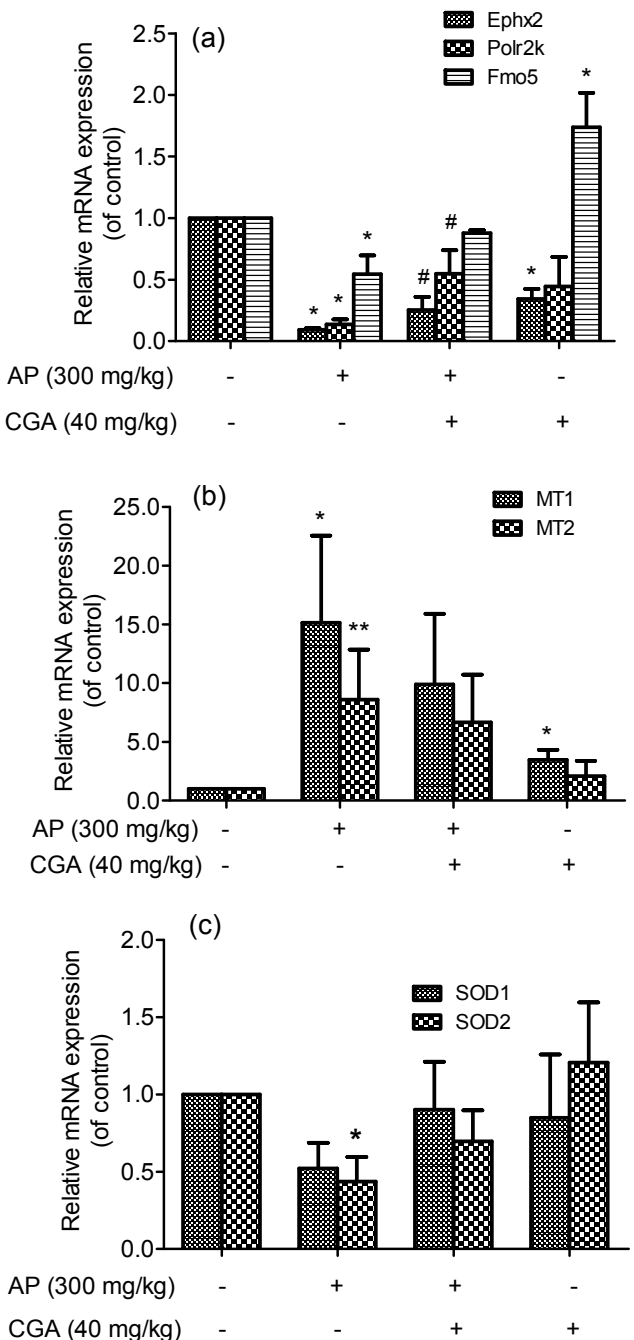

Fig. 5 Effect of CGA on liver mRNA expression of some other oxidative stress genes

Liver mRNA expressions of Ephx2, Polr2k, and Fmo5 (a), MT1 and MT2 (b), SOD1 and SOD2 (c) were detected by real-time PCR. Data are expressed as mean \pm SEM $(n=6-8)$. ${ }^{*} P<0.05,{ }^{* *} P<0.01$ compared with control; ${ }^{\#} P<0.05$ compared with only AP treatment

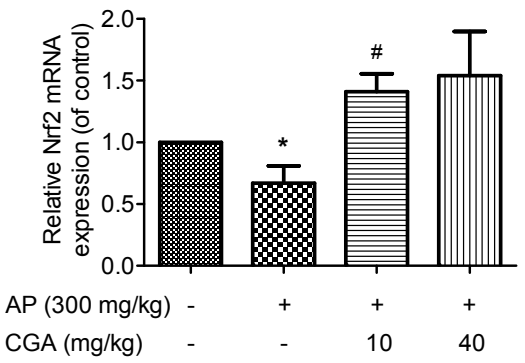

Fig. 6 Effect of CGA on liver Nrf2 mRNA expression Liver mRNA expression of Nrf2 was detected by real-time PCR. Data are expressed as mean $\pm \operatorname{SEM}(n=8) .{ }^{*} P<0.05$ compared with control; ${ }^{\#} P<0.05$ compared with only AP treatment
CGA had no effect on the AP-induced increased mRNA expression of MT1 and MT2 $(P>0.05)$.

As shown in Fig. 5c, AP $(300 \mathrm{mg} / \mathrm{kg})$ decreased liver mRNA expression of superoxide dismutase (SOD) $2(P<0.05)$, but not SOD1 $(P>0.05)$. After CGA $(40 \mathrm{mg} / \mathrm{kg})$ treatment, the AP-induced decreased expression of SOD2 was not altered $(P>0.05)$.

\subsection{Effect of CGA on nuclear factor erythroid-2- related factor 2 (Nrf2) mRNA expression}

Furthermore, the mRNA expression of Nrf2 was observed. As shown in Fig. 6, AP $(300 \mathrm{mg} / \mathrm{kg})$ decreased the liver expression of Nrf2 mRNA $(P<0.05)$, but CGA $(40 \mathrm{mg} / \mathrm{kg}$ ) pre-treatment reversed the decreased Nrf2 mRNA expression $(P<0.05)$.

\section{Discussion}

Liver CYP450 enzymes play a pivotal role in the metabolism of xenobiotics. It has been reported that CYP2E1, CYP3A4, and CYP1A2 are the key CYP450 enzymes for the metabolic activation of AP in human liver, and that the metabolic product of AP in the liver will cause serious hepatotoxicity (Raucy et al., 1989; Laine et al., 2009). In addition, AP has been reported to be metabolized into AM404, which acts on transient receptor potential vanilloid 1 (TRPV1), cyclooxygenase (COX), and endogenous cannabinoid system, contributing to antipyretic and analgesic effects of AP (Högestätt et al., 2005).

Our experiment in vivo demonstrated that CGA itself had no effect on the mRNA expression of CYP2E1, CYP1A2, and CYP3A11 (CYP3A4 in humans) in the liver. In addition, the results of enzymatic activities in vitro showed that CGA displayed weak inhibition on the enzymatic activity of CYP2E1 (less than $40 \%$ inhibition of the positive inhibitor), and CYP1A2 (less than 20\% inhibition of the positive inhibitor). These results indicate that CGA partly prevented AP-induced liver injury via inhibiting the enzymatic activities of CYP2E1 and CYP1A2. It also indicates that there must be other signals involved in the protection of CGA against AP-induced liver injury.

Our previous study found that CGA prevented AP-induced apoptosis and oxidative stress damage, and liver GSH and Trx antioxidant systems played important roles in such protection (Ji et al., 2013). 
The prevention of CGA against AP-induced liver oxidative stress injury was evidenced by the results of MDA, ROS, and GSH levels in this study. Furthermore, we found that some other antioxidant signals also contributed to the protection of CGA against AP-induced liver injury in this study. Prx, a diverse and ubiquitous family of antioxidant proteins, includes six mammalian isoforms: Prx1-6 (Rhee et al., 2005). There are already reports demonstrating that Prx3-knockout increased pyrazole-induced liver oxidative damage (Bae et al., 2012), and Prx6-knockout increased ischemia-reperfusion-induced liver injury (Eismann et al., 2009). In the present study, we found that CGA reversed the decreased mRNA expression of Prx1, 2, 3, 5, and 6 induced by AP. The results suggest that Prx 1, 2, 3, 5, and 6 may play important roles in the protection of CGA against AP-induced liver injury.

Ephx2 is a gene responsible for encoding soluble epoxide hydrolase (sEH), which can metabolize endogenous aliphatic and aromatic epoxides, and plays an important role in regulating cellular redox homeostasis (Fretland and Omiecinski, 2000). Polr2k, an important gene in the RNA processing machinery, has been reported to be associated with cancer (Heidenblad et al., 2008), and the role of Polr $2 k$ in liver injury is still not clear. The present study showed that the mRNA expression of Ephx2 and Polr $2 k$ decreased after AP treatment, and pre-administration of CGA reversed such decrease. Those results indicate the potential involvement of Ephx2 and Polr2k in the CGA protection from AP-induced liver injury.

Fmo is a superfamily of xenobiotic metabolizing enzymes. There are five members of Fmo in humans, of which Fmo5 is highly expressed in the adult liver (Phillips et al., 1995; Zhang and Cashman, 2006). In general, the CYP family is the major contributor to the metabolism of xenobiotic compounds in the liver. However, Fmo may be of significance in a number of cases and should not be overlooked. We found that AP decreased Fmo5 mRNA expression, but CGA failed to increase it. MT is a family of cysteine-rich, low-molecular-weight proteins, and it has been reported to protect against oxidative stress injury induced by exogenous agents (Bauman et al., 1991; Liu et al., 2009). In addition, there is a report that MT-null mice were more susceptible than wild mice to AP-induced hepatotoxicity, whereas zinc pretreat- ment, a method of inducing MT expression, protected against AP-induced hepatotoxicity (Liu et al., 1999). Our present study showed that AP induced MT1 and MT2 mRNA expression, which will contribute to the self-protection of the body against AP-induced liver injury (Saito et al., 2010). However, CGA had no effect on the AP-induced increased mRNA expression of MT1 and MT2. SOD is one of the most important antioxidant enzymes in the body's antioxidant systems, which contains SOD1, SOD2, and SOD3 (McCord and Fridovich, 1969). Our previous study showed that ferulic acid prevented diosbulbin B-induced liver oxidative injury by elevating the decreased mRNA expression of SOD1 (Wang et al., 2014), and thus we suspect that SOD1 and SOD2 may contribute to the detoxification of CGA against AP-induced liver oxidative injury. However, our study showed CGA had no effect on the mRNA expression of SOD1 and SOD2. All these results indicate that Fmo5, MT1, MT2, SOD1, and SOD2 may not contribute to the protection of CGA against AP-induced liver injury.

Nrf2, has emerged as a transcription factor, which is capable of inducing a large variety of antioxidant and detoxification enzymes (Klaassen and Reisman, 2010). Prdx1, Sod1, and Sod2 are all reported to be the target genes regulated by Nrf2 (Kim et al., 2007; Reszka et al., 2015). Previous study showed that the mRNA expression of Nrf2 and Prdx1 were both elevated by quercetin treatment, and thus prevented carbon tetrachloride-induced liver oxidative injury (Zhang et al., 2014). Our results demonstrated that CGA reversed the decreased Nrf2 mRNA expression induced by AP. The results indicate that Nrf2 also contributes to the prevention of CGA against AP-induced liver injury.

In summary, our study demonstrated that CGA ameliorates the AP-induced liver injury only slightly through inhibiting its metabolism. In addition, except GSH and Trx antioxidant systems, some other antioxidant signals such as Prx1, 2, 3, 5, 6, Ephx2, and Nrf2 all contributed to the protection of CGA against AP-induced liver oxidative injury.

\section{Compliance with ethics guidelines}

Chun PANG, Yu-chen SHENG, Ping JIANG, Hai WEI, and Li-li JI declare that they have no conflict of interest.

All institutional and national guidelines for the care and use of laboratory animals were followed. 


\section{References}

Bae, S.H., Sung, S.H., Lee, H.E., et al., 2012. Peroxiredoxin III and sulfiredoxin together protect mice from pyrazoleinduced oxidative liver injury. Antioxid. Redox Signal., 17(10):1351-1361. [doi:10.1089/ars.2011.4334]

Bajt, M.L., Knight, T.R., Lemasters, J.J., et al., 2004. Acetaminophen-induced oxidant stress and cell injury in cultured mouse hepatocytes: protection by $N$-acetyl cysteine. Toxicol. Sci., 80(2):343-349. [doi:10.1093/toxsci/ kfh151]

Bauman, J.W., Liu, J., Liu, Y.P., et al., 1991. Increase in metallothionein produced by chemicals that induce oxidative stress. Toxicol. Appl. Pharmacol., 110(2):347-354. [doi:10.1016/S0041-008X(05)80017-1]

Bebarta, V.S., Kao, L., Froberg, B., et al., 2010. A multi-center comparison of the safety of oral versus intravenous acetylcysteine for treatment of acetaminophen overdose. Clin. Toxicol. (Phila), 48(5):424-430. [doi:10.3109/15563650. 2010.486381]

del Rio, D., Stalmach, A., Calani, L., et al., 2010. Bioavailability of coffee chlorogenic acids and green tea flavan-3-ols. Nutrients, 2(8):820-833. [doi:10.3390/nu20 80820]

dos Santos, M.D., Almeida, M.C., Lopes, N.P., et al., 2006. Evaluation of the anti-inflammatory, analgesic and antipyretic activities of the natural polyphenol chlorogenic acid. Biol. Pharm. Bull., 29(11):2236-2240. [doi:10.1248/ bpb.29.2236]

Eismann, T., Huber, N., Shin, T., et al., 2009. Peroxiredoxin-6 protects against mitochondrial dysfunction and liver injury during ischemia-reperfusion in mice. Am. J. Physiol. Gastrointest. Liver Physiol., 296(2):G266-G274. [doi:10. 1152/ajpgi.90583.2008]

Fretland, A.J., Omiecinski, C.J., 2000. Epoxide hydrolases: biochemistry and molecular biology. Chem. Biol. Interact., 129(1-2):41-59. [doi:10.1016/S0009-2797(00)00197-6]

Gavrilova, V., Kajdzanoska, M., Gjamovski, V., et al., 2011. Separation, characterization and quantification of phenolic compounds in blueberries and red and black currants by HPLC-DAD-ESI-MS ${ }^{n}$. J. Agric. Food Chem., 59(8):4009-4018. [doi:10.1021/jf104565y]

Heidenblad, M., Lindgren, D., Jonson, T., et al., 2008. Tiling resolution array $\mathrm{CGH}$ and high density expression profiling of urothelial carcinomas delineate genomic amplicons and candidate target genes specific for advanced tumors. BMC Med. Genomics, 1:3. [doi:10.1186/17558794-1-3]

Högestätt, E.D., Jönsson, B.A., Ermund, A., et al., 2005. Conversion of acetaminophen to the bioactive $\mathrm{N}$-acylphenolamine AM404 via fatty acid amide hydrolase-dependent arachidonic acid conjugation in the nervous system. J. Biol. Chem., 280(36):31405-31412. [doi:10.1074/jbc.M501489200]

Hunyadi, A., Martins, A., Hsieh, T.J., et al., 2012. Chlorogenic acid and rutin play a major role in the in vivo anti-diabetic activity of Morus alba leaf extract on type II diabetic rats.
PLoS ONE, 7(11):e50619. [doi:10.1371/journal.pone. 0050619]

Ji, L.L., Jiang, P., Lu, B., et al., 2013. Chlorogenic acid, a dietary polyphenol, protects acetaminophen-induced liver injury and its mechanism. J. Nutr. Biochem., 24(11): 1911-1919. [doi:10.1016/j.jnutbio.2013.05.007]

Kasai, H., Fukada, S., Yamaizumi, Z., et al., 2000. Action of chlorogenic acid in vegetables and fruits as an inhibitor of 8-hydroxydeoxyguanosine formation in vitro and in a rat carcinogenesis model. Food Chem. Toxicol., 38(5): 467-471. [doi:10.1016/S0278-6915(00)00014-4]

Kim, J.H., Bogner, P.N., Ramnath, N., et al., 2007. Elevated peroxiredoxin 1, but not NF-E2-related factor 2, is an independent prognostic factor for disease recurrence and reduced survival in stage I non-small cell lung cancer. Clin. Cancer Res., 13(13):3875-3882. [doi:10.1158/10780432.CCR-06-2893]

Klaassen, C.D., Reisman, S.A., 2010. Nrf2 the rescue: effects of the antioxidative/electrophilic response on the liver. Toxicol. Appl. Pharmacol., 244(1):57-65. [doi:10.1016/j. taap.2010.01.013]

Kono, Y., Kobayashi, K., Tagawa, S., et al., 1997. Antioxidant activity of polyphenolics in diets: rate constants of reactions of chlorogenic acid and caffeic acid with reactive species of oxygen and nitrogen. Biochim. Biophys. Acta, 1335(3):335-342. [doi:10.1016/S0304-4165(96)00151-1]

Laine, J.E., Auriola, S., Pasanen, M., et al., 2009. Acetaminophen bioactivation by human cytochrome P450 enzymes and animal microsomes. Xenobiotica, 39(1):11-21. [doi:10. 1080/00498250802512830]

Lee, W.M., 2003. Drug-induced hepatotoxicity. N. Engl. J. Med., 349(5):474-485. [doi:10.1056/NEJMra021844]

Lee, W.M., 2004. Acetaminophen and the U.S. acute liver failure study group: lowering the risks of hepatic failure. Hepatology, 40(1):6-9. [doi:10.1002/hep.20293]

Liang, Q.N., Sheng, Y.C., Jiang, P., et al., 2011. The genderdependent difference of liver GSH antioxidant system in mice and its influence on isoline-induced liver injury. Toxicology, 280(1-2):61-69. [doi:10.1016/j.tox.2010.11. 010]

Liu, J., Liu, Y., Hartley, D., et al., 1999. Metallothionein-I/II knockout mice are sensitive to acetaminophen-induced hepatotoxicity. J. Pharmacol. Exp. Ther., 289(1):580-586.

Liu, J., Zhou, Z.X., Zhang, W., et al., 2009. Changes in hepatic gene expression in response to hepatoprotective levels of zinc. Liver Int., 29(8):1222-1229. [doi:10.1111/j.14783231.2009.02007.x]

McCord, J.M., Fridovich, I., 1969. Superoxide dismutase: an enzymatic function for erythrocuprein (hemocuprein). $J$. Biol. Chem., 244(22):6049-6055.

Oku, H., Ogawa, Y., Iwaoka, E., et al., 2011. Allergypreventive effects of chlorogenic acid and iridoid derivatives from flower buds of Lonicera japonica. Biol. Pharm. Bull., 34(8):1330-1333. [doi:10.1248/bpb.34.1330]

Özyürek, M., Bektaşoğlu, B., Güçlü, K., et al., 2008. Hydroxyl radical scavenging assay of phenolics and flavonoids 
with a modified cupric reducing antioxidant capacity (CUPRAC) method using catalase for hydrogen peroxide degradation. Anal. Chim. Acta, 616(2):196-206. [doi:10. 1016/j.aca.2008.04.033]

Phillips, I.R., Dolphin, C.T., Clair, P., et al., 1995. The molecular biology of the flavin-containing monooxygenases of man. Chem. Biol. Interact., 96(1):17-32. [doi:10.1016/00092797(94)03580-2]

Raucy, J.L., Lasker, J.M., Lieber, C.S., et al., 1989. Acetaminophen activation by human liver cytochromes P450IIE1 and P450IA2. Arch. Biochem. Biophys., 271(1): 270-283. [doi:10.1016/0003-9861(89)90278-6]

Reszka, E., Wieczorek, E., Jablonska, E., et al., 2015. Association between plasma selenium level and NRF2 target genes expression in humans. J. Trace. Elem. Med. Biol., 30:102-106. [doi:10.1016/j.jtemb.2014.11.008]

Rhee, S.G., Chae, H.Z., Kim, K., 2005. Peroxiredoxins: a historical overview and speculative preview of novel mechanisms and emerging concepts in cell signaling. Free Radical Biol. Med., 38(12):1543-1552. [doi:10. 1016/j.freeradbiomed.2005.02.026]

Saito, C., Yan, H.M., Artigues, A., et al., 2010. Mechanism of protection by metallothionein against acetaminophen hepatotoxicity. Toxicol. Appl. Pharmacol., 242(2):182190. [doi:10.1016/j.taap.2009.10.006]

Wang, J.M., Sheng, Y.C., Ji, L.L., et al., 2014. Ferulic acid prevents liver injury and increases the anti-tumor effect of diosbulbin B in vivo. J. Zhejiang Univ.-Sci. B (Biomed. \& Biotechnol.), 15(6):540-547. [doi:10.1631/jzus.B1400104]

Zhang, J., Cashman, J.R., 2006. Quantitative analysis of FMO gene mRNA levels in human tissues. Drug Metab. Dispos., 34(1):19-26. [doi:10.1124/dmd.105.006171]

Zhang, J.Q., Shi, L., Xu, X.N., et al., 2014. Therapeutic detoxification of quercetin against carbon tetrachloride- induced acute liver injury in mice and its mechanism. $J$. Zhejiang Univ.-Sci. B (Biomed. \& Biotechnol.), 15(12): 1039-1047. [doi:10.1631/jzus.B1400104]

\section{中文概要}

题 目: CYP450 代谢酶和一些抗氧化信号参与调控了绿 原酸抑制对乙酰氨基酚的肝毒性

目 的: 本研究旨在观察绿原酸对乙酰氨基酚诱导肝损伤 的解毒作用及其机理。

创新点: 发现 CYP450 代谢酶和一些重要的抗氧化信号分 子 (如 Prx 家族蛋白等) 参与调控了绿原酸抑制 对乙酰氨基酚的肝毒性。

方 法: 检测小鼠血清转氨酶含量, 检测体外 CYP2E1、 CYP3A4 和 CYP1A2 酶活性, 检测肝组织中丙二 醛（MDA）、谷胱甘肽 (GSH) 和活性氧 ( ROS) 含量, 用实时聚合酶链反应（real-time PCR）检 测肝组织中 Prx1-6、Ephx2、Polr2k、Fmo5、Nrf2 等的 mRNA 表达情况。

结 论: 绿原酸可以明显抑制对乙酰氨基酚造成的急性肝 损伤。给药组小鼠血清中的转氨酶与模型组相比 均有显著下降, 绿原酸在体外可以微弱抑制 CYP2E1 和 CYP1A2 代谢酶的活性, 通过 MDA、 GSH 和 ROS 分析发现绿原酸可以抑制对乙酰氨 基酚造成的氧化应激损伤。通过 real-time PCR 分 析发现对乙酰氨基酚降低了抗氧化酶 Prx 家族、 Ephx2、Polr2k 和 Nrf2 的基因表达, 而绿原酸可 以逆转对乙酰氨基酚降低的这些基因的表达。

关键词: 绿原酸; 对乙酰氨基酚; CYP450; 氧应激损伤 